JURNAL RISET MAHASISWA AKUNTANSI

http://ejournal.unikama.ac.id/index.php/jrma

JRMA, Volume 7, No 2, Oktober 2019

\title{
PENGARUH PROFITABILITAS, LEVERAGE DAN INCOME SMOOTHING TERHADAP NILAI PERUSAHAAN PADA PERUSAHAAN MANUFAKTUR YANG TERDAFTAR DI BURSA EFEK INDONESIA (BEI) PERIODE 2016-2018
}

\author{
Ermelinda Owa \\ Email: Owaermelinda@gmail.com \\ Nanang Purwanto \\ Ati Retna Sari
}

Program Studi Akuntansi Fakultas Ekonomika dan Bisnis Universitas Kanjuruhan Malang

\begin{abstract}
ABSTRAK
Nilai perusahaan adalah persepsi investor terhadap tingkat keberhasilan suatu perusahaan. Tingkat keberhasilan suatu perusahaan biasanya sering dikaitkan dengan harga saham. Harga saham yang tinggi membuat nilai perusahaan juga ikut meningkat. Pada penelitian ini, pengambilan sampel dilakukan dengan menggunakan metode purposive sampling. Untuk teknik analisis datanya peneliti menggunakan teknik analisis regresi linear berganda. Dari hasil pengujian hipotesis yang sudah dilakukan, menunjukan bahwa profitabilitas, leverage dan income smoothing secara simultan berpengaruh terhadap nilai perusahaan. Apabila dilihat secara paersial, hasil pengujian hipotesis variabel profitabilitas memiliki pengaruh terhadap nilai perusahaan. Selanjutnya, hasil analisisi variabel leverage juga memiliki pengaruh terhadap variabel nilai perusahaan. Hasil analisis yang keempat menunjutkan bahwa variabel income smoothing berpengaruh terhadap nilai perusahaan. Berdasarkan penelitian yang telah dilakukan maka diajukan saran, bagi para investor sebelum melakukan investasi dapat melihat nilai perusahaannya terlebih dahulu sebagai pertimbangan yang dilakukan sebelum melakukan investasi.
\end{abstract}

Kata Kunci: Profitabilitas, Leverage, Income Smoothing, Nilai Perusahaan

\begin{abstract}
Company value is investors' perception of the level of success of a company. The level of success of a company is usually often associated with stock prices. High stock prices make the value of the company also increased. In this study, sampling was conducted using a purposive sampling method. For the data analysis technique the researchers used multiple linear regression analysis techniques. From the results of hypothesis testing that has been done, it shows that profitability, leverage and income smoothing simultaneously affect the value of the company. When viewed commercially, the results of hypothesis testing profitability variables have an influence on firm value. Furthermore, the results of the analysis of leverage variables also have an influence on firm value variables. The fourth analysis shows that the income smoothing variable affects the value of the company. Based on research that has been done, it is suggested, for investors before investing can see the value of the company first as a consideration made before investing.
\end{abstract}

Keynotes: Profitability, Leverage, Income Smoothing, Company value 


\section{PENDAHULUAN}

Perekonomian global saat ini secara tidak langsung berimbas bagi perekonomian di Indonesia. Keadaan politik dalam negeri jugua dapat mempengaruhi perekonomian di Indonesia. Perekonomian saat ini telah menciptakan suatu persaingan yang sangat ketat dengan perusahaan dalam negeri. Persaingan ini membuat perusahaan semakin meningkatkan kinerja agar tujuannya dapat tercapai. Tujuan utama perusahaan adalah untuk dapat meningkatkan nilai perusahaan serta mensejahterakan pemilik perusahaan (stockholder). Nilai perusahaan akan meningkat apabila harga saham juga meningkat yang ditandai dengan tingkat pengembalian investasi yang tinggi kepada para pemegang saham (Rasyid, 2015). Kinerja yang baik dapat meningkatkan nilai perusahaan serta harga saham perusahaan, hal ini dapat mencerminkan kemakmuran para pemegang saham suatu perusahaan. Perusahaan yang sering mengalami kekurangan modal maka akan berakibat pada kinerja perusahaan barang atau jasa yang dihasilkan kurang maksimal dan perusahaan pun tidak dapat bersaing di pasar sehingga mengalami perkembangan yang lambat.

Profitabilitas merupakan hasil bersih dari berbagai keputusan yang diterapkan oleh sebuah perusahaan. Selain itu, profitabilitas juga didefinisikan sebagai kemampuan perusahaan dalam menghasilkan laba dari penjualan barang/jasa yang diproduksinya. Nilai perusahaan dipengaruhi oleh besar kecilnya profitabilitas yang dihasilkan oleh perusahaan tersebut, karena semakin besar profitabilitas maka akan membuat nilai perusahaan juga semakin tinggi dan membuat para investor berani berinvestasi di perusahaan tersebut.

Leverage merupakan rasio yang dapat menunjukan kemampuan suatu perusahaan untuk memenuhi segala kewajiban finansial dari perusahaan tersebut seandainya perusahaan tersebut dilikuidasi. Leverage juga sebagai salah satu alat yang banyak digunakan perusahaan untuk dapat meningkatkan modal mereka dalam rangka meningkatkan keuntungan. Hutang berasal dari bank dan pembiayaan lainnya. Perusahaan yang terlalu banyak melakukan pembiayaan dengan hutang, dianggap tidak sehat karena dapat menurunkan laba. Peningkatan dan penurunan hutang memiliki pengaruh terhadap penilaian pasar. Kelebihan pasar yang besar akan memberikan dampak negative terhadap nilai perusahaan (Ogolmagai, 2013).

Income smoothing adalah tindakan yang dilakukan dengan sengaja untuk mengurangi variabilitas laba yang dilaporkan agar dapat mengurangi risiko pasar atas saham perusahaan, yang pada akhirnya juga dapat meningkatkan harga saham perusahaan. Definisi income smoothing adalah sebagai upaya yang sengaja dilakukan untuk memperkecil fluktuasi pada tingkat laba yang dianggap normal bagi perusahaan. Income smoothing tidak tergantung pada kecurangan, melainkan pada peluang yang muncul dalam alternatif prinsip-prinsip akuntansi transaksi yang diterimanya.

Objek yang digunakan dalam penelitian ini adalah perusahaan manufaktur yang terdaftar di Bursa Efek Indonesia Periode 2016 sampai 2018. Mengapa peneliti memilih perusahaan manufaktur? Karena perusahaan manufaktur adalah perusahaan industri pengolahaan yang mengelolah bahan baku menjadi barang setengah jadi atau barang jadi. Perusahaan manufaktur identik dengan pabrik yang mengaplikasikan mesin-mesin, peralatan, teknik rekayasa dan tenaga kerja. Istilah ini bisa digunakan untuk aktivitas manusia mulai dari kerajinan tangan sampai ke produksi dengan teknologi tinggi. 
Ermelinda Owa, Pengaruh Profitabilitas, Leverage Dan Income Smoothing Terhadap Nilai Perusahaan Pada

Perusahaan Manufaktur Yang Terdaftar Di Bursa Efek Indonesia (BEI)

KAJIAN PUSTAKA

Nilai Perusahaan

Nilai perusahaan dapat dikatakan sebagai nilai pasar. Hal ini karena nilai pasar dapat memberikan kemakmuran secara maksimal kepada para pemegang saham. Kemakmuran itu diberikan apabila harga saham suatu perusahaan juga meningkat, karena semakin tinggi harga saham, maka semakin tinggi pula nilai suatu perusahaan.

\section{Profitabilitas}

Rasio yang bertujuan untuk mengukur seberapa besar kemampuan perusahaan dalam menghasilkan laba selama suatu periode dan dapat memberikan gambaran tentang tingkat efektivitas manajemen dalam melaksanakan kegiatan operasionalnya (Setia, 2008).

Leverage

Rasio yang menggambarkan hubungan antara utang perusahaan dengan modal perusahaan, serta dapat melihat seberapa jauh suatu perusahaan dibiayai oleh utang. Dalam arti luas, rasio leverage digunakan untuk mengukur sejauh mana perusahaan dibiayai oleh utang (Hery, 2016).

\section{Income Smoothing}

Tindakan yang dilakukan dengan sengaja untuk mengurangi variabilitas laba yang dilaporkan agar dapat mengurangi risiko pasar atas saham perusahaan, yang pada akhirnya dapat meningkatkan harga saham perusahaan.

Kerangka Konseptual Penelitian

Berdasarkan hipotesis yang telah diuraikan di atas, dapat digambarkan kerangka konseptual pada gambar berikut:

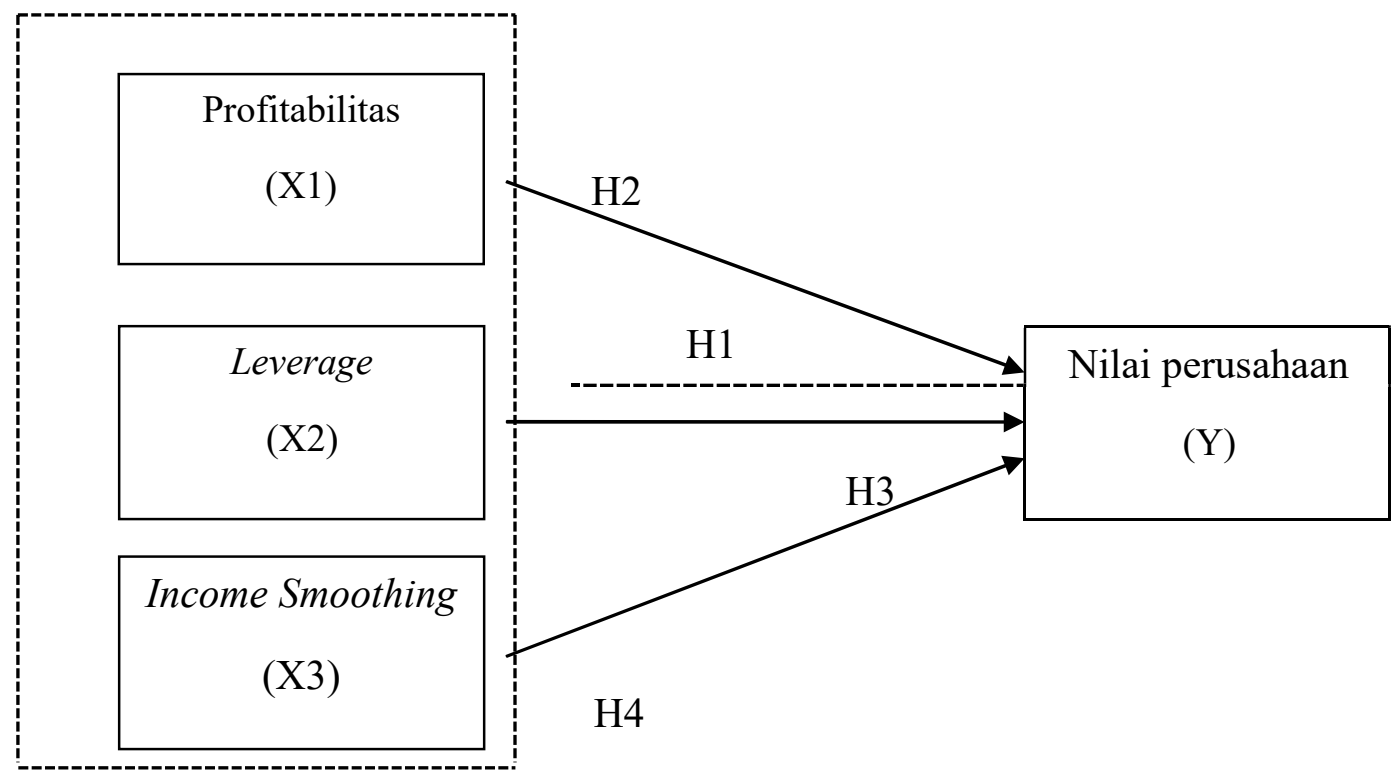

\section{Kerangka Konseptual}




\section{Hipotesis Penelitian}

Berdasarkan kerangka konseptual diatas maka dapat dijabarkan hipotesis sebagai berikut:

$\mathrm{H}_{1}$ : Profitabilitas, leverage dan income smoothing berpengaruh secara simultan terhadap nilai perusahaan.

$\mathrm{H}_{2}$ : Profitabilitas berpengaruh terhadap Nilai Perusahaan. $\mathrm{H}_{3}$ :

Leverage berpengaruh terhadap Nilai Perusahaan.

$\mathrm{H}_{4}$ : Income Smoothing berpengaruh terhadap Nilai Perusahaan.

\section{METODE}

\section{Definisi Operasional Variabel}

Variabel dependen merupakan variabel yang dipengaruhi oleh variabel lain. Dalam penelitian ini variabel dependen adalah nilai perusahaan $(Y)$. Nilai perusahaan diukur dengan menggunakan rasio price to book value (PBV). Rasio nilai perusahaan meurupakan rasio yang membandingkan nilai pasar investasi perusahaan dengan biayanya.

Variabel independen dalam penelitian ini adalah adalah profitabilitas, leverage dan income smoothing. Profitabilitas merupakan rasio yang digunakan untuk mengukur seberapa besar kemampuam perusahaan untuk memperoleh laba yang baik dalam hubungannya dengan penjualan, asset, maupun laba bagi modal itu sendiri. Leverage adalah rasio yang menunjukan seberapa banyak hutang yang digunakan untuk membiayai aset-aset perusahaan Leverage diukur menggunakan Debt to Asset Ratio (DAR) yaitu perbandingan antara jumlah hutang dengan total aktiva. Hal ini berarti semakin tinggi nilai rasio maka semakin tinggi pula risiko bagi kreditur. Dengan demikian besar kecilnya DAR selalu diikuti dengan besar kecilnya risiko, sehingga DAR berpengaruh baik positif maupun negatif. Income smoothing diukur dengan menggunakan Indeks Eckel. Indeks eckel berfungsi sebagai penentu kategori suatu perusahaan apakah melakukan praktik income smoothing atau tidak.

\section{Populasi dan Sampel}

Populasi dan sampel yang digunakan dalam penelitian ini adalah perusahaan manufaktur yang terdaftar di Bursa Efek Indonesia (BEI) periode 2016 sampai 2018 jumlah sampel dalam penelitian ini sebamnyak 45 sampel.

\section{HASIL PENELITIAN DAN PEMBAHASAN Hasil Uji Multikololinieritas}

Berdasarkan hasil output yang telah diolah menunjukan VIF yang diperoleh variabel profitabilitas $\left(\mathrm{X}_{1}\right)$ yaitu sebesar 1.720 , leverage $\left(\mathrm{X}_{2}\right)$ sebesar 1.128, dan income smoothing $\left(\mathrm{X}_{3}\right)$ sebesar 1.886. Dengan demikian, semua variabel independen VIF (Variance Inflation Factor) lebih kecil dari 1 VIIF < 10. Maka dapat disimpulkan bahwa pada model ini tidak terjadi multikololinieritas antar variabel dalam model regresi.

\section{Hasil Uji Autokorelasi}

Hasil output yang diolah menunjukan bahwa nilai Durbin-Waston sebesar 1.991. Hasil yang didapat nilai Durbin-Waston berada diantara d $>4$ - $\mathrm{dL}$ atau 2,550

$>$ 4-1,29. Maka dapat disimpulkan bahwa dalam model regresi yang digunakan dalam penelitian ini terjadi masalah autokorelasi dan dapat digunakan untuk analisis lebih lanjut karena asumsi uji autokorelasi terpenuhi dan dapat dilakukan uji regresi linear berganda.

\section{Hasil Uji Heteroskedastisitas}

Pada penelitian ini uji heteroskedastisitas menggunakan pendekatan motode scatterplot ditemukan telahu terjadi heteroskedastisitas karena terdapat pola bergelombang, melebar, kemudian menyempit. 


\section{Hasil Uji Normalitas}

Pengujian normalitas pada penelitian ini menggunakan metode grafik (Normal Probability Plot). Kriteria uji normalitas menggunakan grafik P-Plot dan dapat dinyatakan berdistribusi normal apabila sebaran data pada grafik berada disekitar garis diagonal serta arah penyebarannya mengikuti garis diagonal.

\section{Hasil Uji Hipotesis}

\section{Pengaruh Profitabilitas, Leverage, dan Income Smoothing terhadap Nilai Perusahaan.}

Hasil penelitian ini menunjukan bahwa secara simultan profitabilitas, leverage dan income smoothing berpengaruh terhadap nilai perusahaan. Hal ini dibuktikan pada hasil statistik uji $\mathrm{F}$ bahwa nilai Sig. sebesar 0.000 yang berarti bahwa variabel $X_{1}, X_{2}$, dan $X_{3}$ berpengaruh terhadap variabel $\mathrm{Y}$. Hasil tersebut dapat dikatakan berpengaruh karena nilai Sig. dibawah 0,05 atau $5 \%$.

Nilai perusahaan diartikan sebagai persepsi investor terhadap tingkat keberhasilan perusahaan yang sering dikaitkan dengan variabel-variabel lain yang memengaruhinya. Memaksimalkan nilai perusahaan dianggap sangat penting bagi suatu perusahaan, karena jika nilai perusahaan maksimal berarti juga memaksimalkan tujuan utama perusahaan. Meningkatnya nilai perusahaan merupakan sebuah prestasi yang sesuai dengan keinginan para pemilik dan investor karena dengan meningkatnya nilai perusahaan, maka kesejahteraan para pemilik juga akan meningkat.

\section{Pengaruh Profitabilitas terhadap Nilai Perusahaan}

Hasil yang diperoleh dari analisis data yaitu menggunakan statistik uji parsial (uji t) menunjukan bahwa nilai profitabilitas $\left(X_{1}\right)$ sebesar 0.000 lebih kecil alpa $5 \%$. Hal ini berarti bahwa secara parsial profitabilitas berpengaruh terhadap nilai perusahaan.

Kesimpulan dari pernyataan diatas yaitu ROA berpengaruh terhadap nilai perusahaan karena semakin tiinggi profitabilitas suatu perusahaan menunjukan semakin besar kemampuan perusahaan menggunakan sumber dananya yang berasal dari internal perusahaan berupa keuntungan dari operasi perusahaan. Investor menanamkan sahamnya adalah untuk mendapatkan return. Semakin tinggi perusahaan memperoleh laba, maka akan semakin besar return yang diharapkan investor sehingga memberikan dampak positif terhadap nilai perusahaan.

\section{Pengaruh Leverage terhadap Nilai Perusahaan}

Leverage $\left(\mathrm{X}_{2}\right)$ berpengaruh terhadap nilai perusahaan. Hal ini menunjukan bahwa hasil uji-t variabel leverage $\left(X_{2}\right)$ sebesar 0.001 lebih kecil alpa 5\%. Hal ini berarti secara parsial leverage berpengaruh terhadap nilai perusahaan. Hal ini menunjukan bahwa rasio leverage adalah rasio yang digunakan untuk mengukur sejauh mana perusahaan dibiayai oleh utang. Penggunaan leverage akan meningkatkan keuntungan yang tinggi bagi pemegang saham, sebaliknya leverage juga dapat meningkatkan risiko keuntungan, karena jika perusahaan ternyata mendapatkan keuntungan yang lebih rendah dari biaya tetapnya maka penggunaan leverage akan menurunkan keuntungan yang akan dicapai oleh pemegang saham, dalam penelitian ini leverage menggunakan metode debt asset ratio digunakan untuk mengukur perbandingan antara total utang dan total asset.

Pengaruh Income Smoothing terhadap Nilai Perusahaan.

Income smoothing berpengaruh terhadap nilai perusahaan pada perusahaan manufaktur yang terdaftar di Bursa Efek Indonesia. Hal ini menunjukan bahwa income smoothing merupakan tindakan yang dilakukan dengan sengaja untuk mengurangi variabilitas laba yang dilaporkan agar dapat mengurangi risiko pasar atas saham perusahaan, yang pada akhirnya dapat meningkatkan harga saham perusahaan. Kesimpulan dari pernyataan tersebut 
yaitu income smoothing berpengaruh terhadap nilai perusahaan karena perusahaan yanng memiliki nilai perusahaan yang tinggi akan cenderung melakukan income smoothing karena dengan melakukan income smootihing, variabilitas laba dan risiko saham dari perusahaan akan menurun. Variabilitas laba yang minim inilah yang berusaha dipertahankan oleh perusahaan agar disukai investor.

\section{PENUTUP}

\section{Kesimpulan}

Penelitian ini bertujuan untuk mengetahui pengaruh profitabilitas, leverage dan income smoothing secara simultan berpengaruh terhadap nilai perusahaan. Berdasarkan pengujian dan hasil analisis yang telah dilakukan dalam penelitian ini dapat disimpulkan bahwa, variabel profitabilitas, leverage dan income smoothing secara simultan berpengaruh terhadap nilai perusahaan pada perusahaan manufaktur yang terdaftar di Bursa Efek Indonesia (BEI) tahun 2016 sampai 2018. Variabel profitabilitas, leverage dan income smoothing secara parsial juga berpengaruh terhadap nilai perusahaan pada perusahaan manufaktur yang terdaftar di Bursa Efek Indonesia (BEI) tahun 2016 sampai 2018. Semakin baik nilai perusahaan maka akan berdampak pada harga saham perusahaan.

\section{DAFTAR PUSTAKA}

Hery.2016. Analisis Laporan Keuangan. Jakarta: Grasindo.

Ogolmagai, Natalia. 2013. Pengaruh Leverage Terhadap Nilai Perusahaan Pada Industri Manufaktur Yang Go Public di Indinesia. Jurnal EMBA 81. 1(3): Hal:81-89.

Rasyid. Al. M. 2015. Analisis pengaruh Modal Kerja terhadap Profitabilitas.

Skripsi. Bandung: Universitas Widyatama.

Setia, Lukas. 2008. Teori dan Praktik Manajemen Keuangan. Yogyakarta: ANDI.

www.idx.co.id 